\title{
Clinical Gerontologist
}

\section{Higher Pain Intensity, Depression and Being 75 Years or Older are Associated with Lower Levels of Self-Reported Physical Activity in Older Adults with Pain Attending Primary Care}

\section{Anabela G. Silva PhD, Alexandra Queirós PhD, Pedro Sá Couto PhD \& Nelson P. Rocha PhD}

To cite this article: Anabela G. Silva PhD, Alexandra Queirós PhD, Pedro Sá Couto PhD \& Nelson P. Rocha PhD (2016): Higher Pain Intensity, Depression and Being 75 Years or Older are Associated with Lower Levels of Self-Reported Physical Activity in Older Adults with Pain Attending Primary Care, Clinical Gerontologist, DOI: 10.1080/07317115.2015.1135839

To link to this article: http://dx.doi.org/10.1080/07317115.2015.1135839

Accepted author version posted online: 12 Jan 2016.

Submit your article to this journal ¿

View related articles $\nearrow$

View Crossmark data $₫$ 


\section{Higher pain intensity, depression and being 75 years or older are associated with lower levels of self- reported physical activity in older adults with pain attending primary care}

Running title: Pain and physical activity

Anabela G. Silva ${ }^{1,2}, \mathrm{PhD}$, Alexandra Queirós ${ }^{1,3}, \mathrm{PhD}$, Pedro Sá Couto ${ }^{4}, \mathrm{PhD}$, Nelson P. Rocha $^{3,5}$, PhD

School of Health Sciences, University of Aveiro, Campus Universitário de Santiago, 3810-193 Aveiro - Portugal

Center for Health Technology and Services Research (CINTESIS), Piso 2, edifício nascente, Rua Dr. Plácido da Costa, s/n, 4200-450 Porto, Portugal

Institute of Electronics and Telematics Engineering of Aveiro (IEETA), University of Aveiro, Campus Universitário de Santiago, 3810-193 Aveiro - Portugal

Center for Research and Development in Mathematics and Applications (CIDMA), Department of Mathematics (DMAT), University of Aveiro, Portugal

Department of Health Sciences, University of Aveiro, Campus Universitário de Santiago, 3810193 Aveiro - Portugal

Corresponding author Anabela G. Silva, PhD Assistant Professor School of Health Sciences, University of Aveiro, Campus Universitário de Santiago, 3810-193 Aveiro - Portugal Telefone: 234401558, extensão: 23899 Fax: 234401597 e-mail: asilva@ua.pt

\section{Abstract}

Objective - This study investigated whether pain characteristics (intensity, frequency, duration and number of pain sites), depression, age, sex and comorbidities are associated with lower levels of self-reported physical activity in older adults with pain at the primary healthcare setting. 
Methods - A total of 504 participants aged 60 years and over were assessed for: sociodemographics, comorbidities, pain, depression and physical activity and associations between these variables investigated using ordinal logistic regression.

Results - Reporting severe pain or worst imaginable pain, being older ( $\geq 75$ years), and feeling depressed were significantly associated with lower physical activity in the univariate (OR=2.33, 2.93, 2.31, and 2.23, respectively) and multivariate models (Adj OR=2.21, 2.47, 2.49, and 1.97, respectively).

Conclusions - Interventions aiming to increase physical activity for older adults in primary care should consider the needs of those reporting higher pain intensity, feeling depressed and who are 75 years or older.

Key words - older adults, physical activity, pain, primary care

\section{Introduction}

The absolute number of people aged 60 years and over is expected to increase from 605 million in 2000 to 2 billion in 2050 (WHO, 2011). Aging is associated with an increase in chronic health conditions, which subsequently increase the risk of functional decline, impact quality of life and challenge the ability of healthcare services to provide timely and appropriate care (Harrison \& Bloom, 2001; WHO, 2011). Therefore, promoting health and well-being is crucial to help older adults maintain an active and independent living. The evidence of the benefits of physical activity in maintaining good health and function is unquestionable. It has been shown that 
increased levels of physical activity are associated with reduced health care use (Jacobs, Rottenberg, Cohen, \& Stessman, 2013; Stessman, Hammerman-Rozenberg, Cohen, Ein-Mor, \& Jacobs, 2009), better management of chronic conditions, delayed decline in function and increased longevity in older adults (Christmas \& Andersen, 2000; Ekblom-Bak, Ekblom, Vikström, de Faire, \& Hellénius, 2014; Stessman et al., 2009). The evidence highlights the need to evaluate physical activity in routine health examinations, implement strategies to improve it and monitor their effectiveness (Trost, Blair, \& Khan, 2014). This seems particularly relevant at the primary healthcare setting, where physical activity could be a cornerstone in the prevention of many common chronic diseases (Angevaren et al., 2007).

The percentage of older adults reaching the recommendations for physical activity levels is lower compared to younger groups (Troiano et al., 2008; Tucker, Welk, \& Beyler, 2011). For example, Tucker, Welk and Beyler ( 2011) reported that $64.4 \%$ of American adults aged 40 to 49 years old met the physical activity guidelines defined as 150 minutes per week of moderate to vigorous physical activity. This percentage decreased to $58.8 \%$ in the group aged 50 to 59 years old and to $46.9 \%$ in the group of older adults aged 70 years old or more. Furthermore, older adults with pain show consistently lower levels of physical activity compared with asymptomatic older adults (Brendon Stubbs et al., 2013), as well as increased sedentary behaviour (Brendon Stubbs, Patchay, Soundy, \& Schofield, 2014). However, older adults with pain are likely to differ in terms of number of pain sites, pain intensity or pain duration, comorbidities or depressive symptoms and it is unknown whether physical activity levels vary among subgroups of patients with chronic pain (Brendon Stubbs et al., 2013). Studies investigating the association between pain characteristics and physical activity have focused on pain intensity only and have reported 
conflicting results (Verbunt et al. 2001; Rabbitts, Holley, Karlson and Palermo, 2014; Grubert, Baker, Mcgeever and Shaw, 2013). Moreover, it has been advocated that intensity is insufficient to fully characterise pain and, for example, number of pain sites and pain duration have been shown to be more strongly associated with physical performance than pain intensity (Eggermont, Bean, Guralnik, \& Leveille, 2009; Hartvigsen, Frederiksen, \& Christensen, 2006). Depression has also been shown to be associated with lower levels of physical activity (Loprinzi, 2013), but whether this association remains in the presence of chronic pain is unclear. Knowing which characteristics of older adults with pain are associated with lower levels of physical activity at the primary healthcare setting will help clinicians to tailor interventions to patients' specific characteristics and needs, what might increase its success. We hypothesized that, in terms of pain characteristics, higher number of pain sites and higher pain intensity will be more strongly associated with lower levels of physical activity that pain frequency or pain duration. In addition, we hypothesized that depression, higher number of comorbidities, female sex and older age will be associated with lower levels of physical activity in older adults with pain. Therefore, the objective of the present study was to determine whether pain characteristics (intensity, frequency, duration and number of pain sites), depression, age, sex and comorbidities are associated with lower levels of self-reported physical activity in older adults with pain at the primary healthcare setting.

\section{Methods}

This study received Ethical approval from the Regional Health Administration Commission, Coimbra, Portugal. All participants signed an informed consent prior to their participation. 


\section{Participants}

Participants were recruited at 18 primary health care practices located across the municipalities of Aveiro, Ílhavo and Vagos, Portugal, among those having a consultation on the day of data collection. Participants were approached by the investigators when waiting for their consultation in the waiting room and invited to participate. Participants could be enrolled in the study if they were $\geq 60$ years old and were able to give written informed consent. This was ascertained by asking participants to explain on their own words what the study involved. The number of participants from each municipality and health care practice was proportional to the population served. This was achieved by performing an a priori sample size calculation considering the total number of inhabitants from the three municipalities aged 18 years old and over, a confidence level of $95 \%$ and a confidence interval of $4 \%$. The total sample size calculated for the study ( $\mathrm{n}=504$ ) was subdivided according to the percent contribution of each municipality, resulting in 259 participants from the municipality of Aveiro, 147 participants from the municipality of Ílhavo and 98 participants from the municipality of Vagos. The number of participants assessed at each primary care practice within the same municipality was calculated based on the percentage of inhabitants served at each practice by sex and age group.

\section{Procedures}

Data were collected in a one session interview. All researchers involved in data collection were previously trained by two of the authors (AGS and AQ). Researchers' training included studying the instruments and methods of application, applying the instruments to participants not included 
in the study and subsequent discussion of results. Demographic and health characteristics, pain, depressive symptoms and physical activity were assessed. The procedures and instruments used are explained below.

\section{Demographic and health characteristics}

Demographic and health characteristics included age, sex and presence of chronic disorders. The presence of the latest was ascertained by asking participants whether they had any of the following conditions: i) hypertension, ii) diabetes, iii) cardiovascular disorders, iv) respiratory disorders, v) cancer, vi) osteoarthritis (back, hip or knee), vii) other known medical condition or viii) any medical condition for which the nature/medical diagnosis was not known. The total number of reported chronic conditions was counted (varying from 0 to 8), a procedure previously used to categorize comorbidities (Fejer \& Hartvigsen, 2008).

\section{Pain intensity, number of pain sites, pain frequency and pain duration}

In the present study, pain intensity (pain intensity considering all the pain sites) in the day of data collection was measured using a $10 \mathrm{~cm}$ vertical numeric graphic rating scale, anchored with 0 (no pain) and 10 (the most severe pain imaginable). For the regression analysis, pain intensity was categorized as: 1 ) no pain (VAS=0); 2) mild pain (VAS=1, 2); 3) moderate pain (VAS=3, 4, 5); 4) severe pain (VAS=6, 7, 8); and 5) worst pain imaginable (VAS=9, 10).

Participants were also asked to mark on a body chart where they felt pain in the week preceding data collection. Posteriorly, the number of pain sites was counted and categorized as 1) single pain site, 2) two pain sites, 3) three or more pain sites but not meeting the criteria for widespread 
pain and 4) widespread pain. Widespread pain was defined as pain in the left and right side of the body, pain above and below the waist and axial-skeletal pain (Wolfe et al., 1990). Both the numeric rating scale and the body chart have been shown to be valid and reliable in older people (Weiner, Peterson, \& Keefe, 1998; Williamson \& Hoggart, 2005).

Pain frequency in the week preceding data collection was assessed using a forced choice question (seldom - once a week; occasionally - 2 to 3 times a week; often - more than 3 times a week; always - all days).

\section{Pain duration was classified as 1) $<6$ months and 2) $\geq 6$ months (i.e. chronic pain).}

\section{Depressive symptoms}

Depressive symptoms were assessed using the short version of the Portuguese translation of the Geriatric Depression Scale (GDS) (Veríssimo, 1998). This is a valid and reliable 15 item selfreport scale of depression initially developed for adults aged 65 years or more (Sheikh \& Yesavage, 1986). However, Weintraub, Saboe and Stern ((2007) showed that its level of sensitivity and specificity for patients aged less than 65 is comparable to that of patients aged more than 65 years. Participants were asked to respond by answering yes or no to each of the 15 items: 10 items indicate the presence of depression when answered positively and 5 indicate depression when answered negatively. A score of 1 is given when the answer is indicative of depression and the total score ranges from 0 to 15 . For the regression analysis we dichotomized the results as 1) no depressive symptoms (4 points or less) and 2) depressive symptoms (5 points or more) (Weintraub, Saboe \& Stern, 2007). 


\section{Physical activity}

Physical activity was assessed using the Portuguese version of the Rapid Assessment of Physical Activity (RAPA) questionnaire (Silva, Queirós, Alvarelhão, \& Rocha, 2014). This questionnaire was specifically designed for use with older adults and it is practical to use in clinical practice as it takes less than 10 minutes to fill in. It has 9 items $(7+2)$. Respondents have to choose one item only from the first seven items (the one that best describes his/her situation in terms of physical activity). Depending on the chosen item, the respondent is then categorized into one of five levels of physical activity: 1) sedentary (Item 1: "I rarely or never do any physical activity"); 2) underactive (Item 2: "I do some light or moderate physical activity, but not every week"); 3) regular underactive, light activities (Item 3: "I do some light physical activity every week"); 4) regular underactive(Item 4: "I do moderate physical activity every week, but for less than 30 minutes a day or five days a week" and Item 5: "I do vigorous physical activity every week, but for less than 20 minutes a day or three days a week"); and 5) regular active (Item 6: "I do 30 minutes or more a day of moderate physical activity, five or more days a week' and Item 7: “I do 20 minutes or more a day of vigorous physical activity, three or more days a week"). The last 2 items are about strength training and flexibility and are answered by individuals reaching item 7 only (Topolski et al., 2006).

\section{Statistical analysis}

Summary statistics were reported as mean and standard deviation for continuous variables and as count and percentage for categorical variables. Chi-squared tests were used to test for significant 
relationships between sex, pain, age, depression and physical activity. The Chi-squared test assumption of no more than $20 \%$ of the cells with an expected value inferior to 5 was verified for all the considered results. A correlation analysis was conducted between the continuous variables using the Spearman's rank correlation test. A one-way ANOVA and an independent t-test were used to test for significant differences in the total number of chronic conditions between participants with different levels of physical activity and between those with and without pain, respectively. The normality of the residuals (assessed using the Smirnov test or by inspection of the Quantile-Quantile plot) and homogeneity of variance (Levene test) assumptions were verified. Univariate and multivariate ordinal logistic regression were used to investigate which variables were associated with physical activity levels as measured by the RAPA questionnaire. Proportional odds ratios (OR), adjusted proportional odds ratios (Adj. OR) and 95\% Confidence Intervals (CI) were calculated for the variables: pain intensity, pain duration, number of pain sites, sex, age, depressive symptoms, and total number of chronic conditions. The absolute correlation coefficients between the independent variables ranged from 0.02 to 0.67 , suggesting that multicollinearity was not present. The model-fitting information presented a significant result and the test of parallel lines indicated that the regression coefficients were the same for all the dependent variable categories. The pseudo $R$-square statistics ranged from $13.9 \%$ and $14.6 \%$. The link function selected was logit (the changes in the cumulative probabilities were gradual), but other link functions were also tested (probit and complementary log-log) with minimal changes in the results. As post hoc analysis, in the multivariate model, multiplicative interactions between significant variables (two at a time) were also tested but the results were non- 
significant. All statistical analyses were performed using SPSS ${ }^{\circledR}$ Software, version 20.0 (SPSS, Inc., Chicago, IL) and p-values under 0.05 were considered significant.

\section{Results}

\section{Sample characteristics and its association with the presence/absence}

\section{of pain.}

A total of 504 participants (338 females) aged (mean \pm SD) 70.9 \pm 7.5 years entered the study. Of the 501 participants for whom physical activity data was available (missing data for 3 participants), 113 (22.6\%) were sedentary, 52 (10.4\%) were underactive, 174 (34.7\%) were underactive light activities, 105 (21.0\%) were regular underactive and 57 (11.4\%) were regular active.

A total of 373 (74.0\%) participants reported pain in at least one body site during the week preceding data collection. Most participants had moderate to severe pain (mean pain intensity at the time of data collection was $5.8 \pm 2.3$ ). In terms of number of pain sites, most participants had multisite or widespread pain (224; 60.1\%). Regarding pain duration, most participants reported chronic pain $(310 ; 83.1 \%)$ and, in terms of pain frequency, most participants (284; 76.1\%) reported pain more than 3 times a week or always (Table 1).

Participants with pain tend to report less physical activity, a higher number of chronic conditions and be more depressed than participants without pain (Table 2). 


\section{Association between physical activity and pain characteristics (pain intensity, pain frequency, pain duration and number of pain sites)}

We found a significant association between physical activity and pain intensity, pain duration and number of pain sites $(\mathrm{p}<0.05)$ and no association between physical activity and pain frequency (Table 3). In the univariate ordinal logistic regression analysis (Table 4) a lower level of physical activity was significantly associated with higher pain intensity (severe and worst imaginable pain: $\mathrm{OR}=2.33$ and $\mathrm{OR}=2.93$ with $\mathrm{p}=0.016$ and $\mathrm{p}=0.013$, respectively), pain duration for 6 months or longer $(\mathrm{OR}=1.85, \mathrm{p}=0.014)$ and multisite pain ( 3 or more pain sites and widespread pain: $\mathrm{OR}=1.85$ and $\mathrm{OR}=2.82$, with $\mathrm{p}=0.016$ and $\mathrm{p}=0.001$, respectively).

\section{Association between physical activity and sex, age, chronic conditions and depression}

A significant relationship was found between physical activity and sex, age and depressive symptoms $(\mathrm{p}<0.05)$ when considering the sub-sample with pain $(\mathrm{n}=373)$ only (Table 3$)$. No association was found between physical activity levels and number of chronic conditions. In the univariate ordinal logistic regression analysis (Table 4) a lower level of physical activity was significantly associated with being depressed $(\mathrm{OR}=2.23, \mathrm{p}<0.001)$ and being 75 years and older $(\mathrm{OR}=2.31, \mathrm{p}=0.001)$. No significant associations were found for sex and chronic conditions. 


\section{Multivariate ordinal regression analysis}

When all independent variables (pain intensity, pain duration, number of pain sites, depression, chronic conditions, age and sex) were entered in the multivariate ordinal regression analysis, only pain intensity, depression and age remained significant (Table 4). Reporting higher pain intensity (severe pain: Adj. OR=2.21, $\mathrm{p}=0.031$; worst pain imaginable: Adj. $\mathrm{OR}=2.47, \mathrm{p}=0.046$ ); having depressive symptoms (Adj. OR=1.97, p=0.001) and being 75 years and older (Adj. $\mathrm{OR}=2.49, \mathrm{p}=0.001$ ) were associated with less physical activity. Of notice, widespread pain (number of pain sites) presented an $\mathrm{Adj}$. $\mathrm{OR}=1.82$ but this result was non-significant ( $\mathrm{p}=0.08)$.No multiplicative effects were found.

A correlation matrix was previously calculated (Table 5), suggesting an association between the dependent and independent variables but no multicollinearity between the independent variables.

\section{Discussion}

This study results suggest that reporting higher pain intensity, being older ( $\geq 75$ years old) and having depressive symptoms are associated with lower levels of physical activity in older adults with pain attending primary care. There was also an association between higher number of pain sites (three or more pain sites and widespread pain) and lower levels of physical activity and between higher pain duration ( $\geq 6$ months) and lower levels of physical activity. However, these associations were not significant in the multivariate ordinal logistic regression analysis. Despite this fact, it is interesting to note that those with widespread pain seem to have a twofold increase 
in the odds of showing lower levels of physical activity (Adj OR=1.82) compared to those reporting one pain site. To our knowledge this is the first study exploring the association between several pain characteristics and physical activity while also considering other potentially influencing factors such as depression and age.

In the multivariate ordinal logistic regression model, having severe to worst imaginable pain, being 75 years and older and having depressive symptoms seems to be associated with lower levels of physical activity. The lower ends of the 95\% CI in the regression models are relatively low, despite their significance. However, this seems to be in line with studies comparing physical activity levels between older adults with and without pain. A meta-analysis of 5 studies and a total of 1,159 older adults with chronic pain established that the levels of physical activity were significantly lower when compared to asymptomatic older adults but that the overall standardized mean difference was small (-0.20, 95\% CI [ -0.34; -0.06]) (Brendon Stubbs et al., 2013). Similar results were found in a systematic review of a subgroup of patients with chronic low back pain (Griffin, Harmon, \& Kennedy, 2012). Systematic review authors reported a standardized mean difference of -0.26 (95\% CI [-0.44; -0.08]) between older adults with chronic low back pain and older adults, without pain (Griffin et al., 2012).

Our findings that higher pain intensity is associated with lower levels of physical activity in older adults with pain attending primary care is in line with the findings of Rabbitts, Holley, Karlson and Palermo (2014), who found an association between pain intensity and subsequent levels of physical activity in adolescents. In addition, Grubert, Baker, Mcgeever and Shaw (2013) reported a $21 \%$ reduction in the odds of moderate/vigorous physical activity among those with moderate 
pain $(\mathrm{OR}=0.79 ; 95 \% \mathrm{CI}[0.71 ; 0.88])$ and a $26 \%$ reduction among those with severe pain (OR=0.74; 95\% CI $[0.61,0.90]$ ) when compared to those without pain in a sample of 11,132 older adults aged 65 years and older. In contrast, Verbunt et al. (2001) found no significant association between pain intensity and objective measurements of physical activity in a sample of 13 adults with low back pain. It is unclear whether the small sample size, the different age group or the different physical activity measurement procedures contributed to the contrasting results.

Regarding depressive symptoms, Julien, Gauvin, Richard, \& Kestens (2013) found that higher depressive symptoms (measured by the GDS) were related to fewer walking days measured at subsequent time points in a population based sample of older adults. Additionally, Loprinzi (2013) investigated the association between objectively measured physical activity and depression among a nationally representative sample of US older adults and reported that for every 60-minute increase in light-intensity physical activity, participants were $20 \%$ less likely to be depressed.

The significant correlation found between pain intensity and depression and the fact that both pain intensity and depression were significantly associated with lower levels of physical activity in the multivariate logistic regression model, suggest that older adults with more intense pain tend to be more depressed and are likely to show higher levels of deconditioning. An increase in physical activity might, in the short term, increase their symptoms leading to a vicious cycle where increased pain with exercise, is followed by less exercise, negative emotions such as depression, higher deconditioning, and more pain, in line with the cognitive behavioral models of 
chronic pain (Main, Sullivan, \& Watson, 2008). This vicious circle needs to be avoided and taken into consideration when planning physical activity interventions. Previous qualitative studies have identified pain intensity and psychological factors as important barriers to participation in physical activity. Participants associate an increase in symptoms due to exercise with the aggravation of the condition, which could make them stop exercising or reduce the amount of their physical activity (Der Ananian et al., 2006; Holden et al., 2012; Holden, Nicholls, Young, Hay, \& Foster, 2014). The perception that physical activity is having no positive impact can be linked to negative emotional responses (Newitt, Barnett, \& Crowe, 2015).

Contrary to our hypotheses, being a female and having a higher number of comorbidities were not associated with lower levels of physical activity. Previous studies have shown that female older adults tend to show lower levels of physical activity than males (Tucker, Welk and Beyler, 2011). However, a previous study in patients with fibromyalgia found no significant differences in the physical activity levels of men and women (Sánchez et al., 2013). While it is possible that pain cancels the physical activity gender difference, it is also possible that this study male participants are not representative of the wider community of older adult males as it is known that men tend to use healthcare services less than women (Owens, 2008). The count of comorbidities was based on participants' self-report and participants might not have accurate knowledge of comorbidities. In addition, total count fails to incorporate disease severity which may be an important factor that mediates the association between comorbidities and physical activity. These need to be considered in future studies. 
The low percentage of participants that achieved recommended levels of physical activity (defined as 150 minutes per week of moderate to vigorous physical activity) even in the group that reported no pain (18.6\%) and the fact that those in the pain group showed lower levels of physical activity (8.9\%) than those without pain highlight the need of strategies to improve physical activity levels for older adults attending primary care. A systematic review aiming to establish global levels of physical activity among older adults (Sun, Norman, \& While, 2013) reported that across the 53 included papers, the percentage of older adults meeting the guidelines varied widely, ranging from $2.4 \%$ to $83.0 \%$, with most studies reporting a percentage between 20 and $60.0 \%$. Another systematic review on the relationship between functional independence and physical activity recommends physical activity above baseline "normal" daily activity levels at an intensity of moderate to moderately vigorous aerobic (endurance) activity, with a total weekly volume of 150 - $180 \mathrm{~min} / \mathrm{wk}$. This physical activity would translate to a $>30 \%$ decrease in the relative risk of morbidity and mortality, and loss of independence, and further benefit would accrue with greater physical activity and greater fitness gains (Paterson \& Warburton, 2010). Furthermore, physical activity as measured in the present study has been found to be associated with both self-reported disability and lower limb performance in older adults (Silva, Queirós, Cerqueira, \& Rocha, 2014), highlighting the importance of promoting physical activity levels. However, the small percentage of older adults achieving the recommended levels of physical activity raises the question as to whether current levels of recommended physical activity might be unattainable for older adults and, in particular, for older adults with pain. Wen et al. (2011) reported that 92 minutes per week or 15 minutes a day of physical activity reduced risk of all-cause mortality in 14\% and increased life expectancy in 3 years, suggesting that lower 
levels of physical activity, more easily attainable, might be adequate to gain health benefits. Furthermore, it is likely that patients are more easily motivated if they think the recommendations could be easily achieved (Wen et al., 2011).

\section{Clinical Implications}

These study results add to the current body of knowledge highlighting the importance of adequate management of pain and depression in older adults. Furthermore, our findings suggest that primary healthcare professionals should routinely assess pain intensity and depression in older adults and may use pain intensity and depression to identify subgroups of older adults with chronic pain more prone to lower levels of physical activity. Whether these subgroups might benefit from strategies that are differentiated in order to meet their needs should also be considered. Additionally, and considering that both pain and depression are associated with falls (Stubbs, Stubbs, Gnanaraj, \& Soundy, 2015; Brendon Stubbs, Binnekade, et al., 2014) and

concerns about falling (Stubbs, Eggermont, Patchay, \& Schofield, 2014), strategies to minimize the risk of falling need to be considered when planning physical activity interventions for older adults with pain.

\section{Study limitations and future research}

The cross-sectional nature of the study does not allow inferences on causal relationships between pain and physical activity. Therefore it is not known whether less physical activity predisposed individuals to pain, increased pain intensity and/or depression or whether pain, pain intensity and/or depression lead participants to reduce physical activity. The use of self-report measures to 
assess physical activity has merit some criticism in favor of more objective ways of quantifying physical activity. However, more objective ways of quantifying physical activity are not always available or practical to use in clinical practice. RAPA has been shown to be valid (Topolski et al., 2006) and has a level of reliability similar to the Physical Activity Scale for the Elderly (PASE), one of the most used physical activity questionnaires (RAPA=0.67; PASE=0.65) (Hagiwara, Ito, Sawai, \& Kazuma, 2008). Nevertheless, future studies using objective measures and subjective measures and higher sample sizes of patients with pain should be implemented. Another limitation is related with the count of comorbidities based on participants' self-report as participants might not have accurate knowledge on comorbidities and total count fails to incorporate disease severity. Our results also suggest that exploring the barriers and facilitators to physical activity across different subgroups of older adults with pain (e.g. those with higher pain intensity; those that are older or depressed) might merit attention as a way of understand the associations found in the present study and help define appropriate prevention/intervention strategies that specifically target the increase of physical activity levels in those more likely to show lower levels of physical activity.

\section{Conclusions}

Reporting higher pain intensity, having depressive symptoms and being 75 years old or more seem to be associated with lower levels of physical activity. The rationale for these associations needs to be further explored in future studies and these factors need to be assessed and considered when designing physical activity interventions directed at older adults with pain attending primary care. 


\section{Acknowledgements}

We would like to thank all people from the Agrupamento de Centros de Saúde Baixo Vouga that directly or indirectly contributed to this work and to the students that contributed to data collection.

Pedro Sá-Couto's work was supported by Portuguese funds through the CIDMA - Center for Research and Development in Mathematics and Applications, and the Portuguese Foundation for Science and Technology (“FCT-Fundação para a Ciência e a Tecnologia”), within project PEstOE/MAT/UI4106/2014.

This research received no specific grant from any funding agency in the public, commercial, or not-for-profit sectors.

\section{Conflict of interests}

Authors declare no conflicts of interest.

\section{References}

Angevaren, M., Aufdemkampe, G., Verhaar, H., Aleman, A., \& Vanhees, L. (2008). Physical activity and enhanced fitness to improve cognitive function in older people without known cognitive impairment. Cochrane Database Syst Rev., 16(3), CD005381.

Christmas, C., \& Andersen, R. (2000). Exercise and older patients: guidelines for the clinician. $J$ Am Geriatr Soc, 48(3), 318-24. 
De Vries, E., Soerjomataram, I Lemmens, V., Coebergh, J., Barendregt, J., Oenema, A., Møller, H., ... Lemmens, V. (2010). Lifestyle changes and reduction of colon cancer incidence in Europe: A scenario study of physical activity promotion and weight reduction. Eur J Cancer., 46(14), 2605-16.

Der Ananian, C., Wilcox, S., Abbott, J., Vrazel, J., Ramsey, C., Sharpe, P., \& Brady, T. (2006). The exercise experience in adults with arthritis: a qualitative approach. Am J Health Behav, 30(6), 731-44.

Eggermont, L., Bean, J., Guralnik, J., \& Leveille, S. (2009). Comparing pain severity versus pain location in the MOBILIZE Boston study: chronic pain and lower extremity function. $J$ Gerontol A Biol Sci Med Sci., 64(7), 763-70.

Ekblom-Bak, E., Ekblom, B., Vikström, M., de Faire, U., \& Hellénius, M. (2014). The importance of non-exercise physical activity for cardiovascular health and longevity. Br J Sports Med, 48(3), 233-8.

Fejer, R., \& Hartvigsen, J. (2008). Neck pain and disability due to neck pain: what is the relation? European Spine Journal: Official Publication of the European Spine Society, the European Spinal Deformity Society, and the European Section of the Cervical Spine Research Society, $17(1), 80-8$.

Griffin, D., Harmon, D., \& Kennedy, N. (2012). Do patients with chronic low back pain have an altered level and/or pattern of physical activity compared to healthy individuals? A systematic review of the literature. Physiotherapy, 98, 13-23. 
Grubert, E., Baker, T. A., Mcgeever, K., \& Shaw, B. A. (2013). The Role of Pain in Understanding the Frequency of Physical Activity Among Older Adults. J Aging Health, 25(3), $1-13$.

Hagiwara, A., Ito, N., Sawai, K., \& Kazuma, K. (2008). Validity and reliability of the Physical Activity Scale for the Elderly (PASE) in Japanese elderly people. Geriatr Gerontol Int., 8(3), $143-51$.

Harrison, G., \& Bloom, M. (2001). Preventative medicine. When to screen for disease in older patients. . 56: Geriatrics, 56, 41-5.

Hartvigsen, J., Frederiksen, H., \& Christensen, K. (2006). Back and neck pain in seniorsprevalence and impact. Eur Spine J, 15(6), 802-6.

Holden, M. A., Nicholls, E. E., Young, J., Hay, E. M., \& Foster, N. E. (2014). Exercise and physical activity in older adults with knee pain: a mixed methods study. Rheumatology, 54(3), 413-23.

Holden, M., Nicholls, E., Young, J., Hay, E., \& Foster, N. (2012). The role of exercise for knee pain: what do older adults in the community think? Arthritis Care Res, 64, 1554-64.

Jacobs, J., Rottenberg, Y., Cohen, A., \& Stessman, J. (2013). Physical activity and health service utilization among older people. J Am Med Dir Assoc, 14(2), 125-9.

Julien, D., Gauvin, L., Richard, L., \& Kestens, Y. (2013). Longitudinal Associations Between Walking Frequency and VoisiNuAge Study, 61(12), 2072-2078. 
Loprinzi, P. D. (2013). Objectively measured light and moderate-to-vigorous physical activity is associated with lower depression levels among older US adults, Aging Ment Health. 2013;17(7):801-5.

Main, C., Sullivan, M., \& Watson, P. (2008). Pain Management: Practical Applications of the Biopsychosocial Perspective in Clinical and Occupational Settings. Elsevier Health Sciences.

Newitt, R., Barnett, F., \& Crowe, M. (2015). Understanding factors that influence participation in physical activity among people with a neuromusculoskeletal condition: a review of qualitative studies. Disabil Rehabil., 26, 1-10.

Owens, G. (2008). Gender differences in health care expenditures, resource utilization, and quality of care. J Manag Care Pharm, 14(3 Suppl), 2-6.

Paterson, D. H., \& Warburton, D. E. (2010). Physical activity and functional limitations in older adults: a systematic review related to Canada’s Physical Activity Guidelines. The International Journal of Behavioral Nutrition and Physical Activity, 7, 38.

Rabbitts, J., Holley, A., Karlson, C., \& Palermo, T. (2014). Bidirectional associations between pain and physical activity in adolescents. Clin J Pain, 30(3), 251-8.

Sánchez, A., Valenza, M., Martínez, M., Miró, E., Diener, F., Lami, M., \& Cáliz, R. (2013). Gender Differences in Pain Experience and Physical Activity of Fibromyalgia Syndrome Patients. Journal of Musculoskeletal Pain, 21(2), 147-55.

Sawatzky, R., Liu-Ambrose, T., Miller, W., \& Marra, C. (2007). Physical activity as a mediator of the impact of chronic conditions on quality of life in older adults. Health Qual Life Outcomes, $5,68$. 
Sheikh, J., \& Yesavage, J. (1986). Geriatric depression scale (GDS): recent evidence and development of a shorter version. Clin Gerontologist, 4, 165-173.

Silva, A. G., Queirós, A., Alvarelhão, J., \& Rocha, N. P. (2014). Rapid Assessment of Physical Activity questionnaire. International Journal of Therapy and Rehabilitation, 21(10), 421-426.

Silva, A. G., Queirós, A., Cerqueira, M., \& NP, R. (2014). Pain intensity is associated with both performance-based disability and self-reported disability in a sample of older adults attending primary health care centers. Disability and Health Journal, 7(4):457-65.

Stessman, J., Hammerman-Rozenberg, R., Cohen, A., Ein-Mor, E., \& Jacobs, J. M. (2009). Physical activity, function, and longevity among the very old. Archives of Internal Medicine, 169(16), 1476-83.

Stubbs, B., Binnekade, T., Eggermont, L., Sepehry, A. a, Patchay, S., \& Schofield, P. (2014). Pain and the risk for falls in community-dwelling older adults: systematic review and metaanalysis. Archives of Physical Medicine and Rehabilitation, 95(1), 175-187.

Stubbs, B., Binnekade, T. T., Soundy, A., Schofield, P., Huijnen, I. P. J., \& Eggermont, L. H. P. (2013). Are Older Adults with Chronic Musculoskeletal Pain Less Active than Older Adults Without Pain? A Systematic Review and Meta-Analysis, 14(9), 1316-1331.

Stubbs, B., Eggermont, L., Patchay, S., \& Schofield, P. (2014). Pain interference is associated with psychological concerns related to falls in community-dwelling older adults: multisite observational study. Phy Ther, 94(10), 1410-20. 
Stubbs, B., Patchay, S., Soundy, A., \& Schofield, P. (2014). The Avoidance of Activities due to Fear of Falling Contributes to Sedentary Behavior among Community-Dwelling Older Adults with Chronic Musculoskeletal Pain: A Multisite, 15(11), 1861-1871.

Stubbs, B., Stubbs, J., Gnanaraj, S., \& Soundy, A. (2015). Falls in older adults with major depressive disorder (MDD): a systematic review and exploratory meta-analysis of prospective studies. Int Psychogeriatr, 3, 1-7.

Sun, F., Norman, I. J., \& While, A. E. (2013). Physical activity in older people: a systematic review. BMC Public Health, 13, 449.

Topolski, T. D., LoGerfo, J., Patrick, D. L., Williams, B., Walwick, J., \& Patrick, M. B. (2006). The Rapid Assessment of Physical Activity (RAPA) among older adults. Preventing Chronic Disease, 3(4), A118.

Troiano, R., Berrigan, D., Dodd, K., Mâsse, L., Tilert, T., \& McDowell, M. (2008). Physical activity in the U.S. measured by accelerometer. Med Sci Sports Exerc, 40(1), 181-8.

Trost, S., Blair, S., \& Khan, K. (2014). Physical inactivity remains the greatest public health problem of the 21st century: evidence, improved methods and solutions using the " 7 investments that work" as a framework. Br J Sports Med, 48(3), 169-70.

Tucker, J. M., Welk, G. J., \& Beyler, N. K. (2011). Physical activity in U.S.: adults compliance with the Physical Activity Guidelines for Americans. American Journal of Preventive Medicine, 40(4), 454-61. 
Verbunt, J., Westerterp, K., van der Heijden, G., Seelen, H., Vlaeyen, J., \& Knottnerus, J. (2001). Physical activity in daily life in patients with chronic low back pain. Arch Phys Med Rehabil., 82(6), 726-30.

Veríssimo, T. (1998). Avaliação diagnóstica dos síndromes demenciais: Escala de Depressão Geriátrica. Porto.

Weiner, D., Peterson, B., \& Keefe, F. (1998). Evaluating persistent pain in long term care residents: what role for pain maps? Pain, 76(1-2), 249-57. Weintraub, D., Saboe, K., \& Stern, M. (2007). Effect of age on geriatric depression scale performance in Parkinson's disease. Mov Disord, 22, 1331-1335.

Wen, C. P., Pui, J., Wai, M., Tsai, M. K., Yang, Y. C., Yuan, T., ... Tsao, C. K. (2011). Minimum amount of physical activity for reduced mortality and extended life expectancy: a prospective cohort study, 6736(11), 1-10.

WHO. (2011). Global health and ageing. (W. U. N. I. of Aging, Ed.).

Williamson, A., \& Hoggart, B. (2005). Pain: a review of three commonly used pain rating scales. J Clin Nurs, 14(7), 798-804.

Wolfe, F., Smythe, H., Yunus, M., Bennett, R., Bombardier, C., Goldenberg, D., ... Al, E. (1990). The American College of Rheumatology 1990 criteria for the Classification of Fibromialgia. Report of the Multicenter Criteria Committee. Arthritis Rheum, 33, 160-172. 
Table 1- Pain characteristics ( $n=373)$.

\begin{tabular}{|l|l|}
\hline Pain characteristics & $\mathbf{n ( \% )}$ \\
\hline Pain frequency (week) & \\
\hline Once & $21(5.6)$ \\
\hline Two or three times & $68(18.2)$ \\
\hline More than three times & $136(36.5)$ \\
\hline Always & $62(16.6)$ \\
\hline Pain intensity (VAS) & \\
\hline Moderate pain & $33(8.8)$ \\
\hline
\end{tabular}




\begin{tabular}{|l|l|}
\hline Worst imaginable pain & $37(9.9)$ \\
\hline Pain duration & \\
\hline$<6$ months & $63(16.9)$ \\
\hline$\geq 6$ months & $310(83.1)$ \\
\hline Number of pain sites & \\
\hline One pain site & $72(19.3)$ \\
\hline Two pain sites & $77(20.6)$ \\
\hline Three or more pain sites & $164(44.0)$ \\
\hline Widespread pain & \\
\hline
\end{tabular}


Table 2 - Sample characteristics and its association with the presence/absence of pain.

\begin{tabular}{|c|c|c|c|c|}
\hline Sample characteristics & $\begin{array}{l}\text { Total } \\
\text { n(\%) }\end{array}$ & $\begin{array}{c}\text { No Pain } \\
\text { n(\%) }\end{array}$ & $\begin{array}{l}\text { Pain } \\
\text { n(\%) }\end{array}$ & $\begin{array}{l}\text { Statistical } \\
\text { result }\end{array}$ \\
\hline Sex & & & & \\
\hline Female & 338(67.1) & $54(41.2)$ & 2 & \multirow{2}{*}{$\begin{array}{l}\mathrm{X}^{2}(1)=1.2 \\
\mathrm{p}=0.282\end{array}$} \\
\hline Male & 166(32.9) & $77(58.8)$ & 89(23.9) & \\
\hline Age & & & & \\
\hline $60-64$ & $123(24.4)$ & $41(31.3)$ & $82(22.0)$ & \multirow{4}{*}{$X^{2}(3)=7.6$} \\
\hline $65-69$ & $112(22.2)$ & $33(25.2)$ & $79(21.2)$ & \\
\hline $70-74$ & $96(19.0)$ & $22(16.8)$ & 74(19.8) & \\
\hline$\geq 75$ & 173(34.3) & $35(26.7)$ & $138(37.0)$ & \\
\hline Physical activity & & & & \\
\hline
\end{tabular}




\begin{tabular}{|c|c|c|c|c|}
\hline Sedentary & $113(22.6)$ & $15(11.6)$ & $98(26.3)$ & \\
\hline Underactive & $52(10.4)$ & $8(6.2)$ & $44(11.8)$ & \\
\hline $\begin{array}{l}\text { Regular underactive light } \\
\text { activities }\end{array}$ & $174(34.7)$ & $46(35.7)$ & $128(34.4)$ & \\
\hline Regular underactive & $105(21.0)$ & 36 (27.9) & $69(18.5)$ & \\
\hline $\begin{array}{l}\text { Regular active/meeting } \\
\text { recommended guidelines }\end{array}$ & $57(11.4)$ & & $33(8.9)$ & \\
\hline GDS & & & & \\
\hline Without depression & $.3)$ & 106(80.9) & $213(57.1)$ & $X^{2}(1)=23.6$ \\
\hline With depressic & $185(36.7)$ & $25(19.1)$ & $160(42.9)$ & \\
\hline $\begin{array}{l}\text { Number of chronic conditions } \\
(\text { Mean } \pm \text { SD) }\end{array}$ & $\begin{array}{l}2.2 \pm 1.2 \\
(n=504)\end{array}$ & $\begin{array}{l}1.6 \pm 1.0 \\
(n=131)\end{array}$ & $\begin{array}{l}2.4 \pm 1.3 \\
(n=373)\end{array}$ & $\begin{array}{l}t(502)=-6.5 \\
p<0.001\end{array}$ \\
\hline
\end{tabular}

GDS - Geriatric Depression Scale; $X^{2}$ - Chi-Square. 
Table 3- Association between physical activity categories and sex, age, pain characteristics (pain frequency, pain intensity, pain duration and number of pain sites) and depression for participants with pain $(\mathrm{n}=373)$.

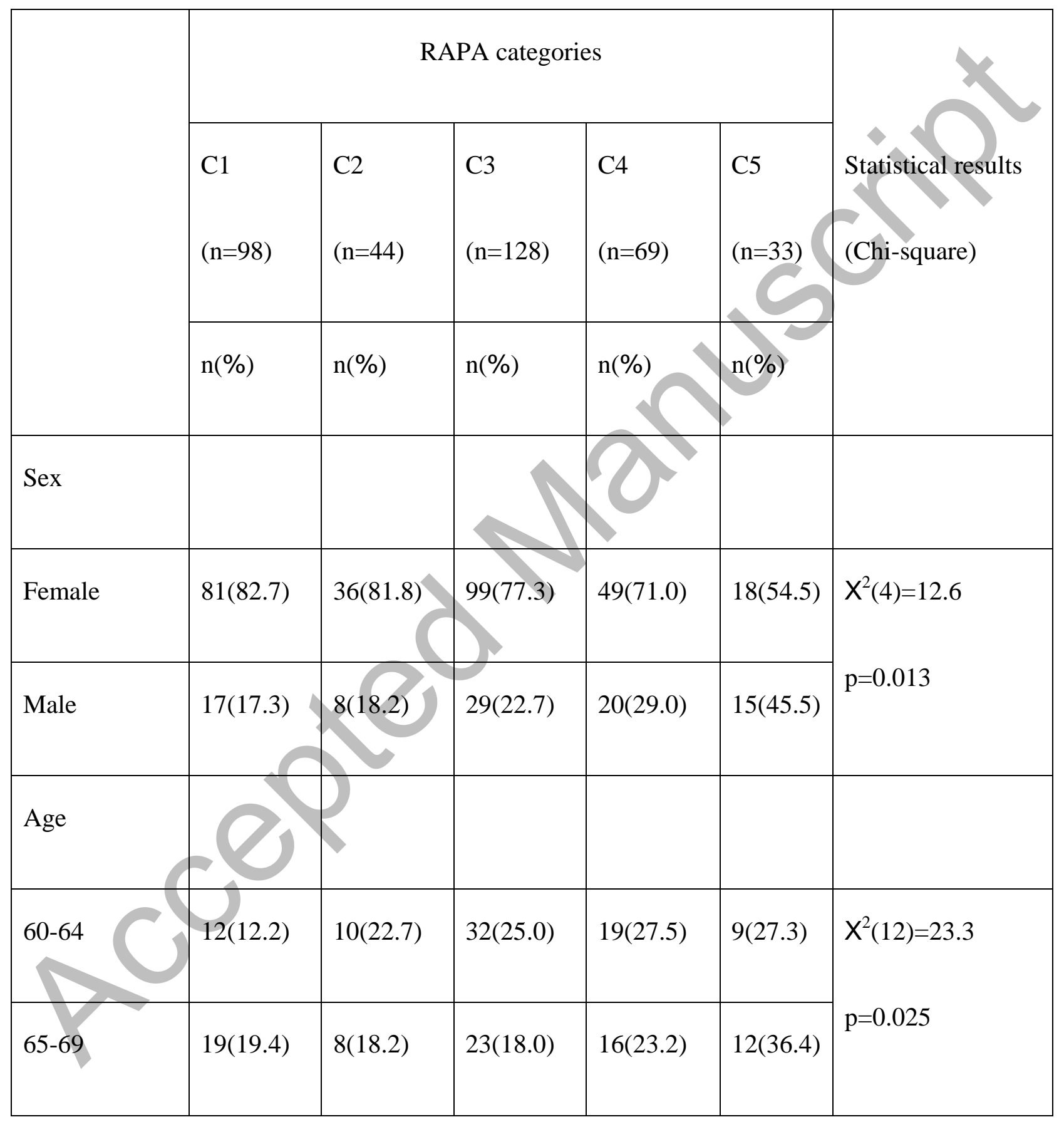




\begin{tabular}{|c|c|c|c|c|c|c|}
\hline $70-74$ & $22(22.4)$ & $4(9.1)$ & $28(21.9)$ & $16(23.2)$ & $4(12.1)$ & \\
\hline$\geq 75$ & $45(45.9)$ & $22(50.0)$ & $45(35.2)$ & $18(26.1)$ & $8(24.2)$ & \\
\hline \multicolumn{7}{|c|}{ Pain frequency (week) } \\
\hline Once & $2(2.0)$ & $2(4.5)$ & $10(7.8)$ & $6(8.7)$ & \multirow{2}{*}{$\frac{1(3.0)}{8(24.2)}$} & \multirow{4}{*}{$X^{2}(12)=15.6$} \\
\hline $\begin{array}{l}\text { Two/three } \\
\text { times }\end{array}$ & 16 (16.3) & $4(9.1)$ & $23(18.0)$ & & & \\
\hline $\begin{array}{l}\text { More than } \\
\text { three times }\end{array}$ & $20(20.4)$ & $5(11.4)$ & 25(19.5) & $8(11.6)$ & $4(12.1)$ & \\
\hline Always & $60(61.2)$ & $33(75.0)$ & $70(54.7)$ & 38(55.1) & $20(60.6)$ & \\
\hline Pain intensity & & & & & & \\
\hline $\begin{array}{l}\text { No pain at the } \\
\text { time of data } \\
\text { collection }\end{array}$ & $6(6.1)$ & $3(6.8)$ & $12(9.4)$ & $7(10.1)$ & $5(15.2)$ & $\begin{array}{l}X^{2}(16)=27.6 \\
p=0.036\end{array}$ \\
\hline
\end{tabular}




\begin{tabular}{|c|c|c|c|c|c|c|}
\hline Mild pain & $3(3.1)$ & $2(4.5)$ & $14(10.9)$ & $7(10.1)$ & $4(12.1)$ & \\
\hline Moderate pain & 33(33.7) & $9(20.5)$ & $52(40.6)$ & $28(40.6)$ & $15(45.5)$ & \\
\hline Severe pain & $41(41.8)$ & $25(56.8)$ & $41(32.0)$ & $21(30.4)$ & $7(21.2)$ & \\
\hline $\begin{array}{l}\text { Worst } \\
\text { imaginable } \\
\text { pain }\end{array}$ & $15(15.3)$ & $5(11.4)$ & $9(7.0)$ & $6(8.7)$ & $2(6.1$ & \\
\hline \multicolumn{7}{|l|}{ Pain duration } \\
\hline$<6$ months & $7(7.1)$ & $11(2$ & 21(16.4) & $17(24.6)$ & $7(21.2)$ & $X^{2}(4)=12.1$ \\
\hline$\geq 6$ months & $91(9$ & $33(75.0)$ & $107(83.6)$ & $52(75.4)$ & $26(78.8)$ & $\mathrm{p}=0.016$ \\
\hline \multicolumn{7}{|c|}{ Number of pain sites } \\
\hline One pain site & 14(14.3) & $7(15.9)$ & $26(20.3)$ & 16(23.2) & $9(27.3)$ & $X^{2}(4)=33.2$ \\
\hline Two pain sites & $12(12.2)$ & $5(11.4)$ & $32(25.0)$ & $17(24.6)$ & 11(33.3) & $\mathrm{p}=0.001$ \\
\hline
\end{tabular}




\begin{tabular}{|c|c|c|c|c|c|c|}
\hline $\begin{array}{l}\text { Three or more } \\
\text { pain sites }\end{array}$ & $45(45.9)$ & 26(59.1) & $56(43.8)$ & $30(43.5)$ & $6(18.2)$ & \\
\hline $\begin{array}{l}\text { Widespread } \\
\text { pain }\end{array}$ & $27(27.6)$ & $6(13.9)$ & $14(10.9)$ & $6(8.7)$ & $7(21.2)$ & \\
\hline GDS & & & & & & \\
\hline $\begin{array}{l}\text { Without } \\
\text { depression }\end{array}$ & $38(38.8)$ & $27(61.4)$ & $77(60.2)$ & & $25(75.8)$ & $\begin{array}{l}X^{2}(4)=20.8 \\
p<0.001\end{array}$ \\
\hline $\begin{array}{l}\text { With } \\
\text { depression }\end{array}$ & $60(61.2)$ & 17(38.6) & 51(39.8) & $24(34.8)$ & $8(24.2)$ & \\
\hline $\begin{array}{l}\text { Number of } \\
\text { chronic }\end{array}$ & 2 & $2.6 \pm 1.1$ & $2.3 \pm 1.3$ & $2.4 \pm 1.4$ & $2.3 \pm 1.4$ & $\begin{array}{l}F(4 ; 367)=1.2 \\
p=0.302\end{array}$ \\
\hline
\end{tabular}

RAPA: Rapid Assessment of Physical Activity; C1: sedentary; C2: under active; C3: regular underactive light activities; C4: regular underactive; C5: regular active; GDS - Geriatric Depression Scale. 
Table 4 - Univariate and multivariate ordinal regressions exploring the association between physical activity and pain intensity, pain duration, number of pain sites, sex, age, depression and number of chronic condition ( $\mathrm{n}=372)$.

\begin{tabular}{|c|c|c|c|c|c|c|}
\hline & \multicolumn{3}{|c|}{ Univariate } & \multicolumn{3}{|c|}{ Multivariate* } \\
\hline & OR & $95 \%$ CI & $\mathrm{p}$ & Adj. & 9 & $\mathrm{p}$ \\
\hline Pain intensity & & & & & & \\
\hline $\begin{array}{l}\text { No pain at the time of data } \\
\text { collection }(n=33)\end{array}$ & 1 & & & 1 & - & - \\
\hline Mild pain $(n=30)$ & & {$[0.34 ; 2.00]$} & 0.666 & 1.01 & $\begin{array}{l}{[0.41 ; 2.52} \\
]\end{array}$ & $\begin{array}{l}0.98 \\
1\end{array}$ \\
\hline Moderate pain & 1.29 & {$[0.65 ; 2.55]$} & 0.526 & 1.37 & $\begin{array}{l}{[0.68 ; 2.76} \\
]\end{array}$ & $\begin{array}{l}0.38 \\
3\end{array}$ \\
\hline Severe pain $(n=135)$ & 2.33 & {$[1.17 ; 4.63]$} & 0.016 & 2.21 & $\begin{array}{l}{[1.08 ; 4.52} \\
]\end{array}$ & $\begin{array}{l}0.03 \\
1\end{array}$ \\
\hline Worst imaginable pain $\quad(n=37)$ & 2.93 & {$[1.25 ; 6.87]$} & 0.013 & 2.47 & {$[1.02 ; 5.98$} & 0.04 \\
\hline
\end{tabular}




\begin{tabular}{|c|c|c|c|c|c|c|}
\hline & & & & & ] & 6 \\
\hline \multicolumn{7}{|l|}{ Pain duration } \\
\hline$<6$ months $(\mathrm{n}=63)$ & 1 & - & - & 1 & & - \\
\hline$\geq 6$ months $(\mathrm{n}=309)$ & 1.85 & {$[1.13 ; 3.02]$} & 0.014 & 1.34 & {$[0.79 ; 2.24$} & 0.27 \\
\hline \multicolumn{7}{|l|}{ Number of pain sites } \\
\hline One pain site $(\mathrm{n}=72)$ & 1 & & - & 1 & - & - \\
\hline Two pain sites $(\mathrm{n}=77)$ & 0.82 & {$[0.46 ; 1.47]$} & 0.518 & 0.85 & {$[0.47 ; 1.55$} & $\begin{array}{l}0.60 \\
3\end{array}$ \\
\hline Three or more pain sites & 1.85 & [1.12;3.05] & 0.016 & 1.53 & $\begin{array}{l}{[0.90 ; 2.94} \\
\text { ] }\end{array}$ & $\begin{array}{l}0.12 \\
2\end{array}$ \\
\hline Widespread pain $(\mathrm{n}=60)$ & 2.82 & {$[1.51 ; 5.27]$} & 0.001 & 1.82 & $\begin{array}{l}{[0.93 ; 3.57} \\
\text { ] }\end{array}$ & $\begin{array}{l}0.08 \\
0\end{array}$ \\
\hline
\end{tabular}




\begin{tabular}{|c|c|c|c|c|c|c|}
\hline Sex & & & & & & \\
\hline Male $(\mathrm{n}=283)$ & 1 & - & - & 1 & - & - \\
\hline Female(n=89) & 1.01 & {$[0.69 ; 1.48]$} & 0.966 & 1.19 & 1.78 & 0.41 \\
\hline Age & & & & & & \\
\hline $60-64(n=82)$ & 1 & & 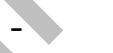 & 1 & - & - \\
\hline $65-69(n=78)$ & 1.13 & {$[0.65$} & 0.654 & 1.09 & $\begin{array}{l}{[0.62 ; 1.91} \\
]\end{array}$ & $\begin{array}{l}0.77 \\
4\end{array}$ \\
\hline $70-74(\mathrm{n}=74)$ & 1.59 & {$[0.90 ; 2.80]$} & 0.108 & 1.62 & $\begin{array}{l}{[0.90 ; 2.93} \\
]\end{array}$ & $\begin{array}{l}0.10 \\
8\end{array}$ \\
\hline$\geq 75(\mathrm{n}=$ & 2.31 & {$[1.40 ; 3.80]$} & 0.001 & 2.49 & $\begin{array}{l}{[1.48 ; 4.19} \\
]\end{array}$ & $\begin{array}{l}0.00 \\
1\end{array}$ \\
\hline GDS & & & & & & \\
\hline
\end{tabular}




\begin{tabular}{|l|l|l|l|l|l|l|}
\hline Without depression (n=212) & 1 & - & - & 1 & - & - \\
\hline With depression (n=160) & 2.23 & {$[1.53 ; 3.25]$} & $<0.001$ & 1.97 & {$[1.33 ; 2.92$} & 0.00 \\
\hline $\begin{array}{l}\text { Number of chronic conditions } \\
(\mathrm{n}=372)\end{array}$ & 1.13 & {$[0.98 ; 1.30]$} & 0.103 & 1.03 & {$[0.89 ; 1.20$} & 0.65 \\
\hline
\end{tabular}

OR - Proportional odds ratio; CI - confidence interval; Adj. OR - Adjusted proportional odds ratio; GDS - Geriatric Depression Scale;

In the multivariate model all independent variables (pain intensity, pain duration, number of pain sites, sex, age, depression and number of chronic conditions) were included simultaneously. 
Table 5- Correlation results between physical activity and the independent variables (Spearman rank test).

\begin{tabular}{|c|c|c|c|c|c|c|c|}
\hline & $\begin{array}{l}\text { Physical } \\
\text { activity }\end{array}$ & $\begin{array}{l}\text { Pain } \\
\text { frequency }\end{array}$ & $\begin{array}{l}\text { Pain } \\
\text { intensity }\end{array}$ & $\begin{array}{l}\text { Pain } \\
\text { duration }\end{array}$ & $\begin{array}{l}\mathrm{N}^{\mathrm{o}} \text { of } \\
\text { pain sites }\end{array}$ & GDS & $\begin{array}{l}\mathrm{N}^{\mathrm{O}} \text { of } \\
\text { chronic }\end{array}$ \\
\hline $\begin{array}{l}\text { Physical } \\
\text { activity }\end{array}$ & 1 & $0.13^{* *}$ & $-0.28 * *$ & $-0.13 * *$ & $-0.29 *$ & -0.20 & $-0.15^{* *}$ \\
\hline $\begin{array}{l}\text { Pain } \\
\text { frequency }\end{array}$ & & 1 & $-0.49 * *$ & & $* *$ & $-0.10^{*}$ & $-0.21 * *$ \\
\hline $\begin{array}{l}\text { Pain } \\
\text { intensity }\end{array}$ & & & & 0.07 & $0.67 * *$ & $0.25^{* *}$ & $0.24^{* *}$ \\
\hline Pain duration & & & & 1 & $0.26 * *$ & 0.10 & 0.05 \\
\hline $\begin{array}{l}\mathrm{N}^{\mathrm{O}} \text { of pain } \\
\text { sites }\end{array}$ & & & & & 1 & $0.27 * *$ & $0.29 * *$ \\
\hline GDS & & & & & & 1 & $0.18^{* *}$ \\
\hline
\end{tabular}




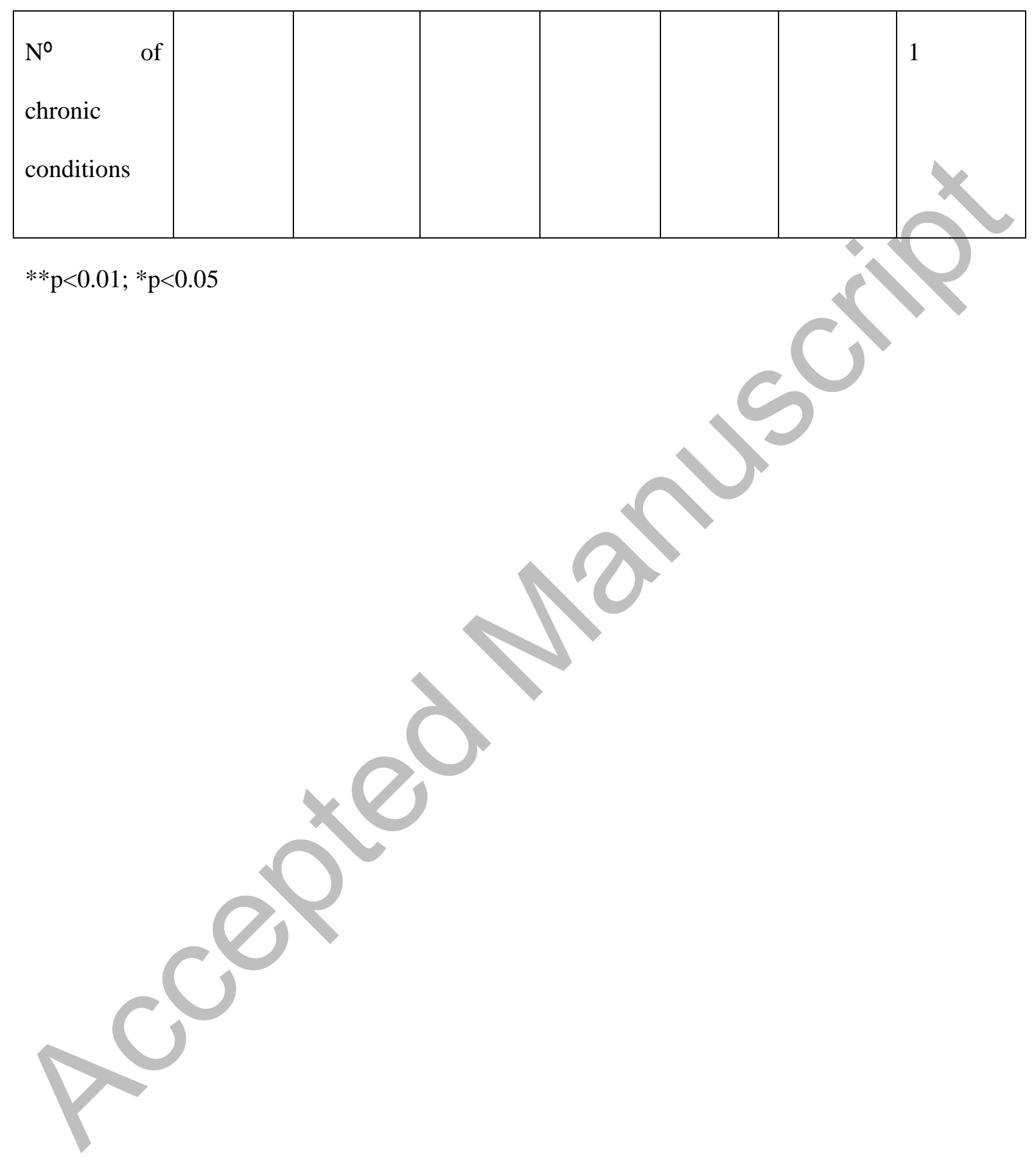

